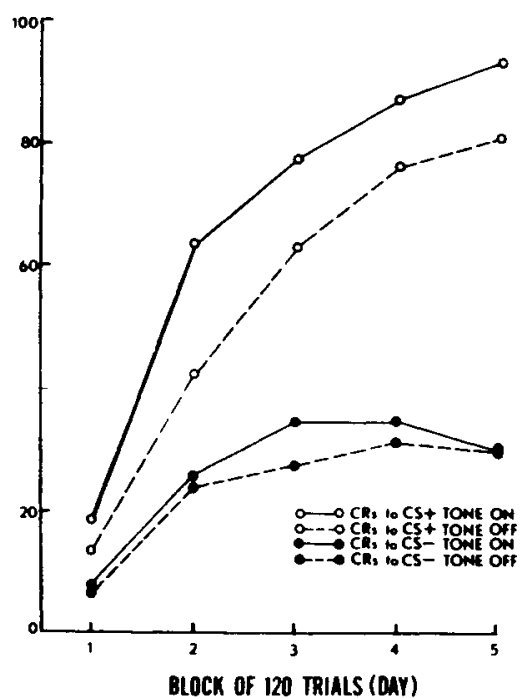

Fig. 1. Comparison of tone-on and tone-off procedure in differential conditioning.

design represented two levels of separation $(\Delta \mathrm{f})$ between $\mathrm{CS}+$ and $\mathrm{CS}-\mathrm{:} 1700$ and $300 \mathrm{~Hz}$ or 1100 and $900 \mathrm{~Hz}$ (counterbalanced); the other dimension referred to the presence or absence of a $1000-\mathrm{Hz}$ tone which occupied the entire ITI. The ITI averaged $60 \mathrm{sec}$ and the ISI was $250 \mathrm{msec}$. Other aspects of the procedure were the same as in the previous experiment.

Results and Discussion

The results were completely opposed to what had been expected on the basis of our experiments with humans. With the small separation between $\mathrm{CS}+$ and $\mathrm{CS}$ $(\Delta \mathrm{f}=200)$, responding to $\mathrm{CS}+$ and $\mathrm{CS}-$ following Day 1 was $81 \%$ and $70 \%$ with the intertrial tone and $79 \%$ and $72 \%$ without. Neither of these differences were statistically significant. Figure 2 shows that with the large separation $(\Delta f=1400)$ the ITS tended to disrupt differentiation over Days 2 and $3(F=6.20, d f=1 / 14, p<.05)$. Unlike human $S s$, these rabbits did not use the intervening tone as an "anchor" or "perceptual boundary," and the intertrial tone, rather than having an inhibitory influence, seemed to mediate or bridge the generalization of excitation from $\mathrm{CS}+$ to CS-.

An explanation of the difference between the two preparations might lie in differences in "spontaneous" intertrial responding. In human eyelid conditioning the intertrial blink rate averages one every $3 \mathrm{sec}$. According to the Perkins-Logan hypothesis (cf. Champion, 1962), the fact that these responses are never reinforced could account for the accrual of inhibition to an intertrial tone in human eyelid conditioning. This inhibition can enhance differentiation through induction and generalization

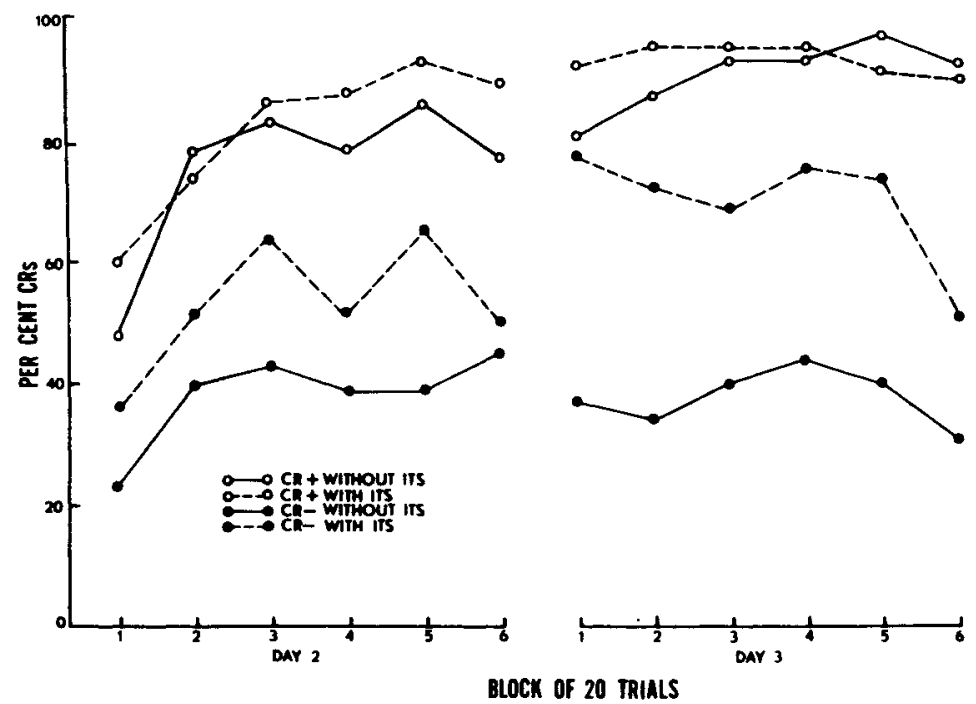

Fig. 2. The effect of an intermediate intertrial tone on differential conditioning of the rabbit nictitating membrane response to tones differing by $1400 \mathrm{~Hz}$.

effects, but in rabbits, where intertrial responding is rare, this source of inhibition would be absent. Frey \& Ross (1967) failed to find any evidence of induction in their analysis of sequential dependencies in differential eyelid conditioning with the rabbit. It is therefore possible that an intertrial tone would not improve differentiation relative to noise even if it did possess inhibitory properties.

\section{REFERENCES}

CHAMPION, R. A. Stimulus-intensity effects in response evocation. Psychological Review, $1962,69,428-449$

FREY, P. W., \& ROSS, L. E. Differential conditioning of the rabbit's eyelid response with an examination of Pavlov's induction hypothesis. Journal of Comparative \& Phy siological Psychology, 1967, 64, 277-283.
MATTSON, M., \& MOORE, J. W. Intertrial responding and CS intensity in classical eyelid conditioning. Journal of Experimen tal Psy chology, 1964, 68, 396-401.

MOORE, J. W., \& NEWMAN, F. L. Intertrial stimuli and generalization of the conditioned eyelid response. Journal of Experimental Psychology, 1966, 71, 414-419.

MOORE, J.W., NEWMAN, F. L., \& GLASGOW, B. Intertrial cues as discriminative stimuli in human eyelid conditioning. Journal of Experimental Psychology, in press.

O'MALLEY, P., HUPKA, R. B., \& MOORE, J. W. Auditory differential conditioning of the rabbit nictitating membrane response: I. Effects of mixed- and separate-phase training. Psychonomic Science, 1969, 15, 123-124.

NOTE

1. This research was supported by NSF Grant GB-5480.

\title{
Auditory differential conditioning of the rabbit nictitating membrane response: V. Stimulus generalization as a function of the position of CS+ and CS- on the frequency dimension'
}

RALPH B. HUPKA, SHIRLEY S. LIU, and JOHN W. MOORE, University of Massachusetts, Amherst, Mass. 01002

Three groups of 16 rabbits were given 5 days of differential conditioning in which the reinforced (CS+) and nonreinforced conditioned stimulus ( $C S-$ ) were presented equally often in a random sequence. The CSs for the three groups were 400 and 1600. 1600 and 2800, 2800 and $4000 \mathrm{~Hz}$, respectively, and for half of the Ss the higher tone was CSt. Differentiation was optimal with tones of 400 and $1600 \mathrm{~Hz}$ and poorest with 2800 and $4000 \mathrm{~Hz}$. Following differential conditioning the same Ss were given 2 
days of generalization tests. The results revealed stimulus control was most pronounced in Ss which received CSs of 400 and $1600 \mathrm{~Hz}$.

Siegel, Hearst, George, \& O'Neal (1968) have reported decremental generalization gradients for the conditioned eyelid response of individual rabbits along the auditory frequency scale. Their animals received conditioning to a single $\mathrm{CS}$ prior to the generalization tests. While the peak of the observed gradients occurred at the training stimulus, there was a tendency for greater generalization at frequencies higher than the training value. These observations were subsequently confirmed by us for the nictitating membrane response of the rabbit. The purpose of this experiment was to examine the relationship between generalization and differential conditioning. If the two are inversely related, then on the basis of the results from single-stimulus studies such as Siegel et al (1968), one would expect poorer discrimination performance with relatively high tonal frequencies and relatively good differentiation at the lower end of the scale. The effect of differential conditioning upon generalization was also investigated in two extinction sessions.

\section{SUBJECTS}

The Ss were 48 naive male and female New Zealand White rabbits, 90-120 days old.

\section{APPARATUS}

A detailed description of the apparatus and technique for recording from the nictitating membrane has been provided in a previous report (O'Malley, Hupka, \& Moore, 1969).

\section{PROCEDURE}

Three groups of 16 Ss received 5 days of conventional differential conditioning (i.e., the reinforced and nonreinforced conditioned stimuli were presented equally often in a random sequence) for 120 trials/day with a fixed separation between the reinforced (CS + ) and nonreinforced conditioned stimulus (CS-) of $1200 \mathrm{~Hz}$. The three groups differed with respect to the location of the CSs on the $\mathrm{Hz}$ scale: The CSs were 400 and 1600,1600 and 2800, 2800 and $4000 \mathrm{~Hz}$, respectively, and for half of the Ss the higher tone was CSt. The intertrial interval averaged $50 \mathrm{sec}$ and the CS-UCS interval was $250 \mathrm{msec}$. A conditioned response (CR) was defined as any $1-\mathrm{mm}$ positive deflection of the recording pen within the interstimulus interval. The UCS consisted of a $2 \cdot \mathrm{mA}$ ac shock of 50-msec duration applied to wound-clip electrodes on the infra-orbital region of the right eye. The generalization tests were carried out during 2 days of extinction, and each of seven test tones $(400,800,1600$, $2200,2800,3400,4000 \mathrm{~Hz}$ ) in each group was presented 17 times in a random order on each day.

\section{RESULTS AND DISCUSSION}

Figure 1 shows that, as anticipated, differential conditioning was best with tones of 400 and $1600 \mathrm{~Hz}$, followed by the 1600 and $2800-\mathrm{Hz}$ group, and with the poorest separation of percentages of CRs to CS+ and CS- occurring when 2800 was paired with $4000 \quad(F=38.33, \mathrm{df}=2 / 36, \mathrm{p}<.001)$. Although the level of conditioning was highest when the lower tone was CS+ $(F=8.31, d f=2 / 36, p<.005)$, the degree of differentiation as measured by the percentage of CRs to CS+ minus the percentage of CRs to CS- did not vary significantly with whether the higher or lower tone was CSt. The overall mean percentage of CRs for the three groups was $.52, .53$, and .41 for Groups $400-1600$, $1600-2800$, and $2800-4000$, respectively $(F=4.13, \mathrm{df}=2 / 36, \mathrm{p}<.025)$. The lower level of responding in the latter groups was due mainly to poor conditioning by those Ss who received the $4000 \mathrm{~Hz}$ as CSt. The general tendency for CSs of lower frequency to be more effective for conditioning agrees with the findings of Siegel et al (1968).

Figure 2 shows the mean absolute generalization gradients for each of the six subgroups of eight Ss. Each point refers to the mean percentage of CRs to each test stimulus and not to percentage of total CRs to all stimuli. These gradients are essentially what would be expected on the basis of the differential conditioning curves. Stimulus control (steepness of the gradient) was most pronounced on the low end of the $\mathrm{Hz}$ scale
$(400 \mathrm{~Hz})$ and poorest at the high end $(4000 \mathrm{~Hz})$, with the intervening values of CS+ yielding an intermediate degree of stimulus control. Generally speaking, then, generalization and differentiation were inversely related in this experiment. This is not to say that generalization merely reflects a failure to discriminate, as is proposed by the Lashley-Wade argument.

A peak shift away from CS- appeared in the group for which 1600 was CSt and 400 was CS-, but it dropped out after Day 1. The fact that peak shifting following differential conditioning was absent elsewhere may indicate that reliable peak shifting, which is relatively easy to obtain following conventional operant discrimination training (Terrace, 1966), does not occur in classical conditioning of the rabbit. Such a conclusion appears plausible in view of Terrace's suggestion that peak shifting in instrumental reward situations depends upon aversive properties of the $S \Delta$. Obviously, the CS- in defensive conditioning cannot be viewed in these terms. However, it may be possible to demonstrate peak shifting in this preparation with more training, greater similarity between $\mathrm{CS}+$ and CS-, or both.

\section{GENERAL DISCUSSION}

This and our previous experiments have revealed some points of similarity between differential conditioning of the nictitating membrane response of the rabbit and the human eyelid response. O'Malley, Hupka, \& Moore (1969) showed an underlying continuity between mixed- and separatephase training procedures, and major trends

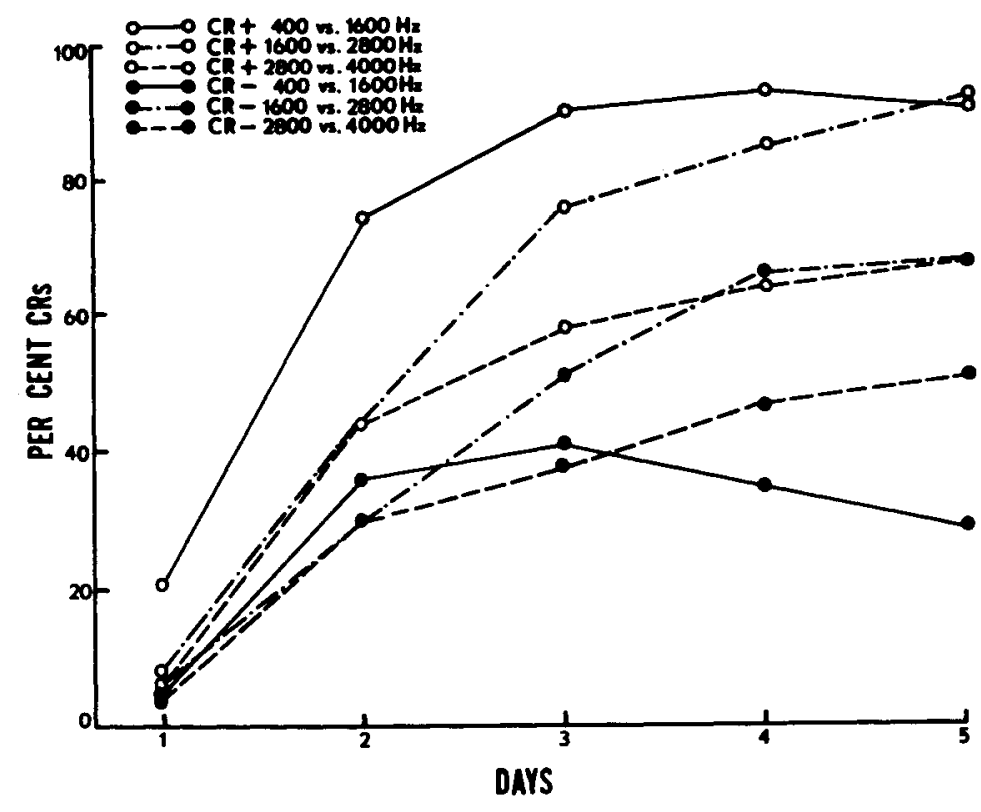

Fig. 1. Differential conditioning with a fixed frequency separation of $1200 \mathrm{~Hz}$ as a function of tonal frequency. 

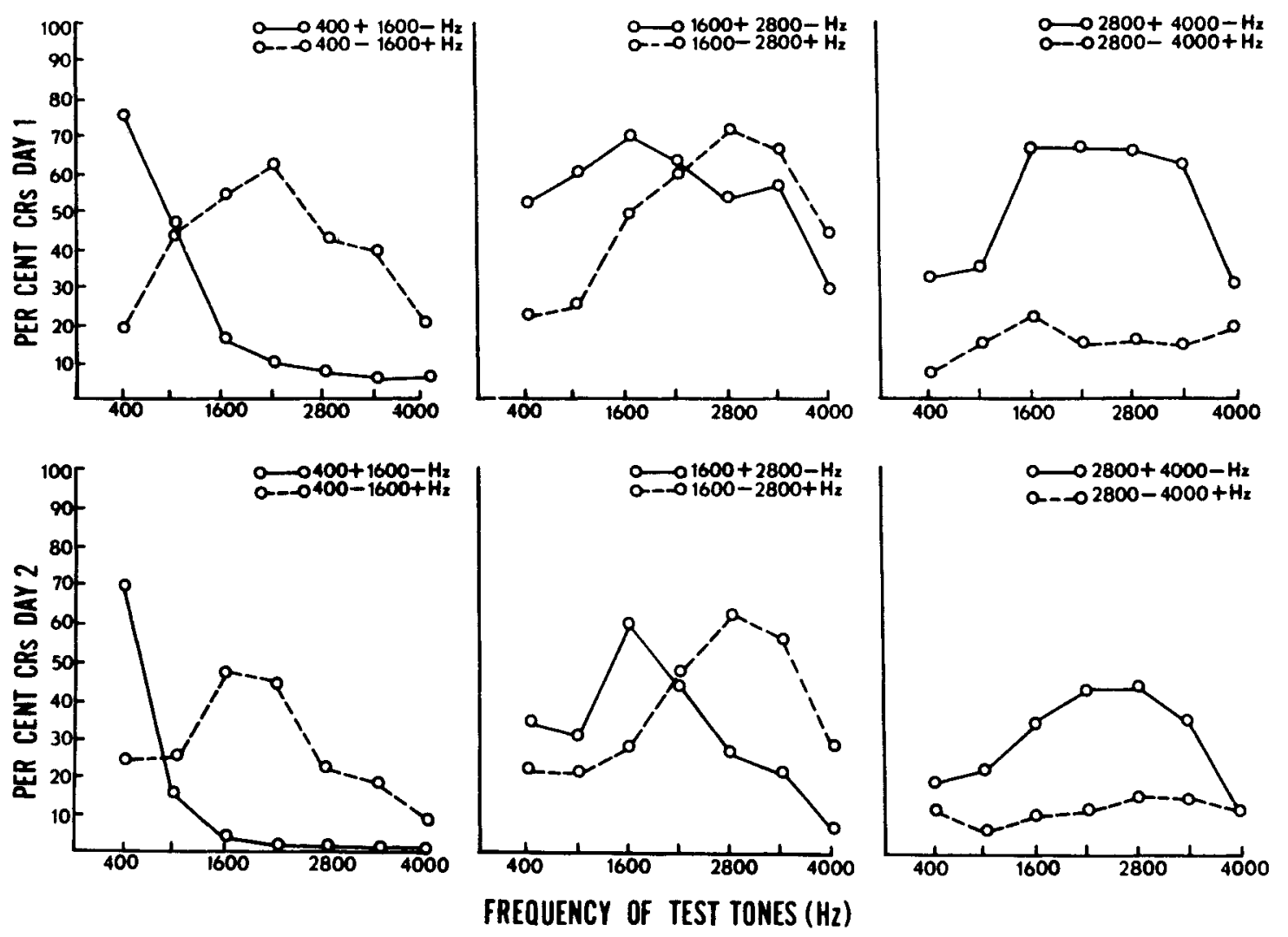

Fig. 2. Stimulus generalization following differential conditioning as a function of tonal frequency.

of the results can be readily interpreted in terms of the same simple conditioningextinction theory of discrimination learning which has been successfully applied to human differential eyelid conditioning. Liu \& Moore (1969) showed that rabbits, like humans, can be conditioned to tone offset and can differentiate between the offset of two intertrial tones almost as readily as they differentiate between the onset of different tones.

Some important differences between the rabbit and human in differential conditioning were also noted. For the most part these involved a comparative weakness or insen. sitivity of inhibitory processes in the rabbit. For example, Chisholm, Hupka, \& Moore (1969) found that good differential conditioning could be obtained with all CS-UCS intervals tested. Compared with human eyelid conditioning, this suggests that the growth of inhibition to CS- depends only on the number of nonreinforced trials and is independent of the CS-UCS interval. Chisholm et al found that partial reinforcement did not produce the sort of performance decrement, relative to responding to CS+ with discriminably different CSs and the same reinforcement schedule, which is customarily observed with human Ss. Partially reinforced $S s$ did condition somewhat more slowly than differential groups, but this tendency was transitory and did not reach statistical significance. Evidently, the amount of inhibition accruing under partial reinforcement is slight when compared with human Ss. Finally, Liu \& Moore (1969) showed that a constant intertrial tone interfered with differentiation by elevating responding to $\mathrm{CS}-$ and, therefore, does not possess the inhibitory properties which it has with human Ss.

Thus far, it has been tacitly assumed that two processes, excitation and inhibition, govern differential conditioning. However, except for the unusually low level of responding to $\mathrm{CS}+$ in the $\Delta \mathrm{f}=200$ groups of Chisholm et al, there is little compelling evidence of an active inhibitory role for CS-. The fact that CS- comes to evoke fewer CRs than CS+ might reflect nothing more than a generalization decrement involving a unitary excitatory process. The possible total absence of inhibition is suggested by the finding that, with one exception, peak shifting was not observed in the postdifferentiation gradients of this experiment. Frey \& Ross' (1967) failure to find definitive induction effects adds further weight to this possibility. We are currently investigating this question more closely by comparing generalization gradients obtained with various inter- and intradimensional differentiation procedures with those obtained without any differential conditioning. We are also attempting to demonstrate inhibitory gradients along a $\mathrm{CS}$ dimension which is orthogonal to CS+. REFERENCES

FREY, P. W., \& ROSS, L. E. Differential conditioning of the rabbit's eyelid response with an examination of Pavlov's induction hypothesis. Journal of Comparative \& Physiological Psychology, 1967, 64, 277-283.

CHISHOLM, D. C., HUPKA, R. B., \& MOORE, J. $W$. Auditory differential conditioning of the rabbit nictitating membrane response: II. Effects of interstimulus interval and cue similarity. Psychonomic Science, 1969, 15, 125-126.

LIU, S. S., \& MOORE, J. W. Auditory differential conditioning of the rabbit nictitating membrane response: III. Training based on stimulus offset and the effect of an intertrial tone. Psychonomic Science, $1969,15,127-128$.

O'MALLEY, P., HUPKA, R. B., \& MOORE, J. W. Auditory differential conditioning of the rabbit nictitating membrane response: I. Effects of mixed- and separate-phase training. Psychonomic Science, 1969, 15, 123-124.

SIEGEL, S., HEARST, E., GEORGE, N., \& O'NEAL, E. Generalization gradients obtained from individual subjects following classical conditioning. Journal of Experimen tal Psy chology, 1968, 78, 171-174.

TERRACE, H. S. Stimulus control. In W. K. Honig (Ed.), Operant behavior: Areas of research and application. New York: Appleton-CenturyCrofts, 1966.

NOTE

1. This research was supported by NSF Grant GB-5480. 